\title{
The association between pre pregnancy body mass index and risk of preeclampsia: a registry based study from Tanzania
}

\author{
Dorah Mrema ${ }^{1,2}$, Rolv Terje Lie ${ }^{1,3}$, Truls Østbye ${ }^{1}$, Michael Johnson Mahande ${ }^{4}$ and Anne Kjersti Daltveit ${ }^{1,3^{*}}$ (D)
}

\begin{abstract}
Background: Preeclampsia is among the leading causes of maternal mortality and morbidity worldwide, occurs in $2-8 \%$ of all pregnancies, and is estimated to account for at least $9 \%$ of maternal deaths in Africa. Studies from developed countries show that high pre pregnancy body mass index (BMI) increases the risk of preeclampsia. We examined the association between pre pregnancy BMI and the risk of preeclampsia in Tanzania, a low income country.

Methods: Data from the Kilimanjaro Christian Medical Center (KCMC) Medical Birth Registry recorded between July 2000 and May 2013 were used. We restricted the study population to singleton deliveries among women with no or one previous pregnancy. Pre pregnancy BMI $\left(\mathrm{kg} / \mathrm{m}^{2)}\right.$ was categorized according to the WHO categories of underweight (less than 18.5), normal (18.5 - 24.9), overweight (25.0 - 29.9) and obese (30 or more). Potential confounders were adjusted for in multivariable analyses.
\end{abstract}

Results: Among the 17,738 singleton births, $6.6 \%$ of the mothers were underweight, $62.1 \%$ were of normal BMI, 24.0\% were overweight, and 7.3\% were obese. Five hundred and eighty-two pregnancies (3.3\%) were affected by preeclampsia. Compared to those with normal BMI, overweight and obese women had a higher risk of preeclampsia (aOR $(95 \% \mathrm{Cl}) 1.4(1.2-1.8)$ and $1.8(1.3-2.4))$, respectively, while underweight women had a lower risk (0.7 (0.4-1.1)).

Conclusions: Pre pregnancy maternal overweight and obesity were associated with an increased risk of preeclampsia in Tanzania. Risks were similar to those reported in high income countries.

Keywords: Preeclampsia, Obesity, BMI, Low income countries, Birth registry, Tanzania

\section{Background}

Preeclampsia is a serious complication affecting $2-8 \%$ of all pregnancies. Globally, more than 287,000 women die each year due to pregnancy related causes [1], of which $10-15 \%$ are estimated to be due to preeclampsia. Most maternal deaths occur in developing countries. Millennium Development Goal number five is to reduce maternal mortality by three quarters by 2015. Given the high number of maternal deaths in low income countries due to preeclampsia, both prevention of preeclampsia and optimal management of preeclamptic pregnancies are important to further reduce maternal mortality [2].

\footnotetext{
* Correspondence: anne.daltveit@uib.no

${ }^{1}$ Department of Global Public Health and Primary Care, Faculty of Medicine, University of Bergen, Postboks 7804, N-5020 Bergen, Norway

${ }^{3}$ Norwegian Institute of Public Health, Bergen, Norway

Full list of author information is available at the end of the article
}

The etiology of preeclampsia remains unclear, but mechanisms related to the placenta, genes, immune response, insulin resistance, and maternal vascular disease are suggested to contribute [3-6]. Established risk factors for preeclampsia include nulliparity, advanced maternal age, overweight/obesity, chronic hypertension, diabetes, previous preeclampsia, family history of preeclampsia, long time since previous pregnancy, and multiple pregnancy [7]. Obesity has been associated with a 2-4 fold increased risk of preeclampsia in different populations [812], and is a leading identified attributable risk for this disorder. A population based study from Dar Es Salaam, Tanzania, reported that the prevalence of obesity among women of reproductive age increased progressively from $3.6 \%$ in 1995 to $9.1 \%$ in 2004 [13]. The Tanzanian Demographic Health Survey for the years 2004 and 2005 
reported a prevalence of $13 \%$ and $4 \%$, respectively of overweight and obesity among women of reproductive age [14].

Since clinical records of births are lacking or not suitable for research in many African countries, studies on preeclampsia in women of African descent have been mostly based on immigrants to high income countries or descendants of immigrants [15]. Some studies have reported that women of African origin are at increased risk of preeclampsia, but it is not clear to which extent this is explained by the presence of specific risk factors for preeclampsia. Also studies on the association between preeclampsia and obesity are mainly based on women in resource rich countries [16].

Etiology, epidemiology and cultural significance of overweight and obesity likely vary from population to population. There are also indications that the course and outcome of preeclamptic pregnancies differs by race and ethnicity [17]. These aspects call for collection of high quality data to study overweight and obesity as risk factors of preeclampsia in indigenous African women. We aimed to examine the association between pre pregnancy BMI and development of preeclampsia in a low income setting in Tanzania. A secondary aim was to explore to which extent this association can be explained by maternal disease before pregnancy (hypertension, heart disease, diabetes).

\section{Methods}

\section{Study design, setting, source of data and population}

This is a registry-based study using existing prospectively collected birth registry data from Kilimanjaro Christian Medical Centre (KCMC). KCMC is a zonal hospital based in Moshi urban district, Kilimanjaro region in Northern Tanzania. The medical birth registry at $\mathrm{KCMC}$ was established in collaboration with researchers at the Department of Global Public Health and Primary Care (formerly Department of Public Health and Primary Health Care) at the University of Bergen Norway, and has been in operation since July 2000. The data were collected by obstetricians and midwives from all women who delivered at KCMC from July 2000 to May 2013. Trained nurse midwives conduct a face to face interview in the hospital, using a standardized questionnaire for all mothers within $24 \mathrm{~h}$ after delivery, or later in case of caesarean section or other complications [18]. The questionnaire is based on check boxes and text boxes. Since the mothers are discharged within $24 \mathrm{~h}$ after a normal delivery, the interviews are done on a daily basis including public holidays and weekends. Abstracted data from files relating to each mother, written by obstetricians, are also included. In addition, mothers admitted to the hospital are asked to provide their antenatal (ANC) cards for further clarification regarding their pregnancy records including pre pregnancy weight and height. This should limit the possibility of recall bias. In summary, the information collected during interview and through inspection of medical files included parents' social-demographic characteristics, reproductive history, pregnancy and birth characteristics such as; maternal health before pregnancy, maternal health during pregnancy, and complications during labour and delivery, and newborn health status. Our sample includes mothers who delivered at Kilimanjaro Christian Medical Centre (KCMC) from July 2000 to May 2013. The mother's records were linked to their children's records using a unique maternal hospital number assigned for each woman who deliver at KCMC for the first time. A total of 46,030 deliveries were recorded. We restricted the study population to women with no or one previous pregnancy. Definition of pregnancy order was based on information about previous pregnancies in the questionnaire including pregnancies lasting less than 28 weeks. Compared to a selection based on previous stillbirths and live births only, exclusion of such early losses reduced the study population by $6 \%$. Exclusion of women with more than one previous pregnancy was done in order to focus on baseline BMI and not BMI as a result of high parity. We excluded multifetal pregnancies, women who were referred for delivery at KCMC from the rural area for medical reasons, and those with missing information on weight or height (Fig. 1). Our final sample consisted of 17,738 singleton births.

\section{Study variables and definitions}

The main outcome of interest was preeclampsia. In the registry's manual, preeclampsia is defined as gestational hypertension of at least $140 / 90 \mathrm{mmHg}$, measured on two separate occasions at least four hours apart, and accompanied by proteinuria, arising after the 20th week of gestation in a previously normotensive woman. This includes mild preeclampsia (blood pressure lower than 160/110) and severe preeclampsia (blood pressure 160/ 110 or higher). The main exposure variable was pre pregnancy BMI based on maternal pre pregnancy weight in kilograms and maternal height in centimetres from antenatal care (ANC) visits. If weight was lacking in the record, self-reported weight was used if reasonable. In a secondary analysis we used gestational age at delivery as a proxy for preeclampsia severity and analysed preeclampsia in connection with term delivery (gestational age 37 or more weeks) and preeclampsia in connection with preterm delivery (gestational age below 37 weeks), as separate outcomes. We excluded women whose records had a height $<130 \mathrm{~cm}$ or $>200 \mathrm{~cm}$ and women whose records had a weight $<35 \mathrm{~kg}$ or $>120 \mathrm{~kg}$. BMI was calculated as body weight in $\mathrm{kg} /$ height in metres squared, and we excluded records with BMI above 40 (0.4\%) and BMI below 15 (0.5\%). Exclusions of records based on recorded height, weight and BMI were 


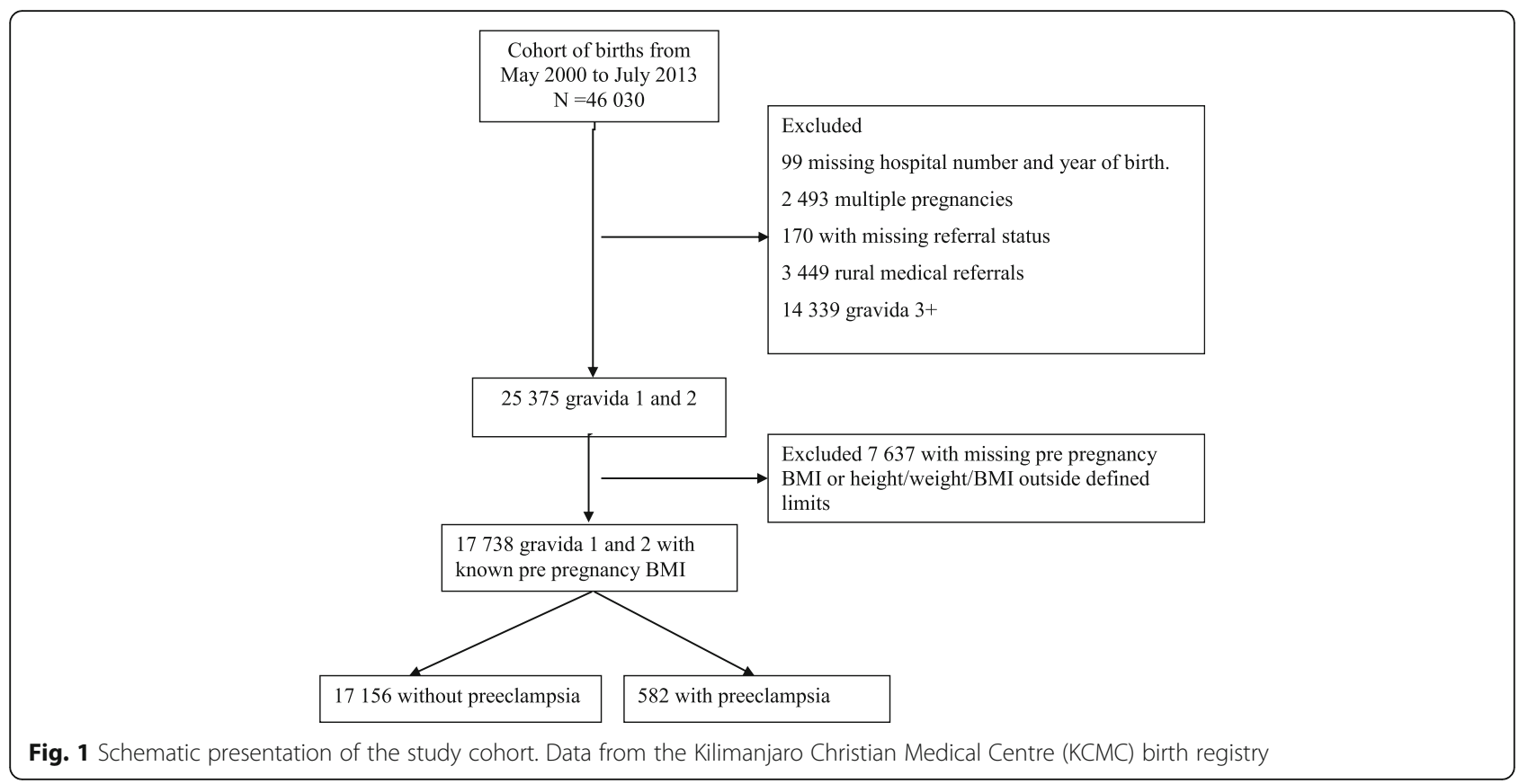

performed to reduce potential effects of typing errors. We categorised BMI according to WHO definitions as underweight $<18.5$, normal weight 18.5-24.9, overweight 25.0-29.9, and obese $\geq 30$.

\section{Data analysis}

Descriptive statistics including means and proportions were calculated. Pearson Chi-square statistics was used to assess associations between BMI categories and categorical factors, and between categorical factors and preeclampsia.. The significance level was set at $p \leq 0.05$ (2-tailed). Binary and multivariable logistic regression analysis was performed to assess the strength of association between the independent variables and preeclampsia. Unadjusted and adjusted odds ratios with $95 \%$ confidence intervals were reported. The ordinal variables (mother's BMI, age, education and height) were also included as continuous covariates in the model to explore a possible dose-response relationship with preeclampsia. $P$-values for trend were reported from this analysis.

We a priori selected a set of potential confounders (mother's age, number of previous pregnancies, mother's education, antenatal care visits, marital status, mother's occupation, mother's tribe, and mother's height). In a second step we included some accompanying medical conditions in the multivariable model; chronic hypertension, diabetes mellitus, and heart diseases before pregnancy. These factors may be a result of the main exposure BMI and should not be considered as pure confounders. However, since they are known to be associated with both BMI and preeclampsia, we wanted to explore the extent to which the association between BMI and preeclampsia was explained by these factors.

All the selected potential confounders were associated with preeclampsia with a $p$-value less than 0.1 in the univariate analysis and were included in the final model. Records with missing values were included only in the descriptive analysis of the participant characteristics. Since for each variable in the multivariable model the proportion of missing values was less than $1 \%$, individuals with missing values on any independent variable were not included in the model. We also tested for interaction between maternal height $(<160 \mathrm{~cm}$ vs $\geq 160 \mathrm{~cm})$ and BMI, and between gestational age $(<37$ weeks, $\geq$ 37 weeks) and BMI, in their impact on risk of preeclampsia, by adding an interaction term in the model. In the interaction analyses BMI was included as a continuous variable.

We also used a clustered analysis technique with robust estimation of variances to account for correlation between successive births from the same mother.

Data were analysed using Statistical Package for Social Sciences (SPSS) version 20 for Windows.

\section{Results}

Of the 17,738 singleton births, overall pre pregnancy mean BMI was 23.5, 6.6\% were births to underweight mothers, $62.1 \%$ to normal weight mothers, $24.0 \%$ to overweight mothers and 7.3\% to obese mothers (Table 1). The highest mean BMI and highest proportion with obesity were found among women above 35 years of age, women who had the highest education, women with missing information on marital status, business or 
Table 1 Sociodemographic characteristics of the participants by BMI $\left(\mathrm{kg} / \mathrm{m}^{2}\right)$ category; 17,738 singleton first or second deliveries. KCMC Medical birth registry July 2000-May 2013

\begin{tabular}{|c|c|c|c|c|c|c|c|}
\hline Characteristics & $\mathrm{N}$ & $\begin{array}{l}\text { Mean (SD) } \\
\text { BMI }\end{array}$ & $\begin{array}{l}\mathrm{BMI}<18.5 \\
\text { Underweight }\end{array}$ & $\begin{array}{l}\text { BMI 18.5-24.9 } \\
\text { Normal }\end{array}$ & $\begin{array}{l}\text { BMI 25.0-29.9 } \\
\text { Overweight }\end{array}$ & $\begin{array}{l}\text { BMI }>=30 \\
\text { Obese }\end{array}$ & $\begin{array}{l}x^{2} \\
p \text {-value }\end{array}$ \\
\hline Overall (n) & 17,738 & & 1178 & 11,008 & 4258 & 1294 & \\
\hline$\%$ & & 23.5 & 6.6 & 62.1 & 24.0 & 7.3 & \\
\hline Mothers age (yrs) & & & & & & & $<0.001$ \\
\hline $\begin{array}{l}13-19 \\
20-24 \\
25-29 \\
30-34 \\
35-50 \\
\text { Missing }\end{array}$ & $\begin{array}{l}2151 \\
6437 \\
5755 \\
2606 \\
755 \\
34\end{array}$ & $\begin{array}{l}21.8(3.2) \\
22.8(3.6) \\
24.0(4.0) \\
24.9(4.2) \\
25.6(4.4) \\
23.9(3.6)\end{array}$ & $\begin{array}{l}12.6 \\
7.9 \\
5.1 \\
3.2 \\
2.9 \\
-\end{array}$ & $\begin{array}{l}72.1 \\
68.3 \\
58.3 \\
51.0 \\
46.5 \\
64.7\end{array}$ & $\begin{array}{l}13.5 \\
19.5 \\
27.7 \\
33.0 \\
33.8 \\
23.5\end{array}$ & $\begin{array}{l}1.8 \\
4.3 \\
8.9 \\
12.9 \\
16.8 \\
8.8\end{array}$ & \\
\hline Mothers education & & & & & & & $<0.001$ \\
\hline $\begin{array}{l}\text { None } \\
\text { Primary } \\
\text { Secondary (8-11 yrs) } \\
\text { Higher (12+ yrs) } \\
\text { Missing }\end{array}$ & $\begin{array}{l}177 \\
9116 \\
1143 \\
7277 \\
26\end{array}$ & $\begin{array}{l}22.8(3.3) \\
23.2(3.8) \\
23.2(4.0) \\
24.0(4.1) \\
23.5(3.4)\end{array}$ & $\begin{array}{l}9.0 \\
7.2 \\
8.7 \\
5.6 \\
11.5\end{array}$ & $\begin{array}{l}69.5 \\
75.5 \\
62.6 \\
57.6 \\
73.1\end{array}$ & $\begin{array}{l}18.1 \\
21.4 \\
23.1 \\
27.6 \\
15.4\end{array}$ & $\begin{array}{l}3.4 \\
6.0 \\
6.7 \\
9.1 \\
-\end{array}$ & \\
\hline Marital status & & & & & & & $<0.001$ \\
\hline $\begin{array}{l}\text { With partner } \\
\text { Without partner } \\
\text { Missing }\end{array}$ & $\begin{array}{l}14,807 \\
2866 \\
65\end{array}$ & $\begin{array}{l}23.6(3.9) \\
23.1(4.1) \\
24.3(4.4)\end{array}$ & $\begin{array}{l}6.2 \\
8.9 \\
4.6\end{array}$ & $\begin{array}{l}61.8 \\
63.4 \\
58.5\end{array}$ & $\begin{array}{l}24.7 \\
20.7 \\
24.6\end{array}$ & $\begin{array}{l}7.3 \\
7.0 \\
12.4\end{array}$ & \\
\hline Mother's occupation & & & & & & & $<0.001$ \\
\hline $\begin{array}{l}\text { Housewife } \\
\text { Farmer } \\
\text { Service } \\
\text { Business } \\
\text { Professional } \\
\text { Student } \\
\text { Missing }\end{array}$ & $\begin{array}{l}3567 \\
2784 \\
1286 \\
4125 \\
3790 \\
592 \\
1594\end{array}$ & $\begin{array}{l}23.0(3.7) \\
22.5(3.5) \\
23.8(3.9) \\
24.2(4.2) \\
24.2(4.0) \\
22.4(3.8) \\
23.1(3.8)\end{array}$ & $\begin{array}{l}8.2 \\
9.1 \\
5.2 \\
5.4 \\
4.4 \\
12.0 \\
6.8\end{array}$ & $\begin{array}{l}65.9 \\
70.0 \\
59.9 \\
56.7 \\
57.0 \\
65.4 \\
66.1\end{array}$ & $\begin{array}{l}20.8 \\
17.3 \\
27.4 \\
27.3 \\
29.1 \\
17.9 \\
21.9\end{array}$ & $\begin{array}{l}5.1 \\
3.6 \\
7.5 \\
10.7 \\
9.6 \\
4.7 \\
5.2\end{array}$ & \\
\hline Mothers tribe & & & & & & & $<0.001$ \\
\hline $\begin{array}{l}\text { Chagga } \\
\text { Pare } \\
\text { Other }\end{array}$ & $\begin{array}{l}10,164 \\
2044 \\
5530\end{array}$ & $\begin{array}{l}23.8(4.0) \\
23.5(4.0) \\
23.0(3.9)\end{array}$ & $\begin{array}{l}5.4 \\
7.3 \\
8.7\end{array}$ & $\begin{array}{l}60.2 \\
62.2 \\
65.4\end{array}$ & $\begin{array}{l}26.1 \\
23.6 \\
20.2\end{array}$ & $\begin{array}{l}8.2 \\
6.8 \\
5.7\end{array}$ & \\
\hline Antenatal care & & & & & & & $<0.001$ \\
\hline $\begin{array}{l}<4 \\
\geq 4 \\
\text { Missing }\end{array}$ & $\begin{array}{l}8742 \\
8783 \\
213\end{array}$ & $\begin{array}{l}23.4(4.0) \\
23.7(3.9) \\
23.1(3.7)\end{array}$ & $\begin{array}{l}7.3 \\
5.9 \\
10.3\end{array}$ & $\begin{array}{l}63.4 \\
60.7 \\
60.1\end{array}$ & $\begin{array}{l}22.3 \\
25.7 \\
24.9\end{array}$ & $\begin{array}{l}7.0 \\
7.6 \\
4.7\end{array}$ & \\
\hline Mother's height & & & & & & & $<0.001$ \\
\hline $\begin{array}{l}<155 \mathrm{~cm} \\
155 \mathrm{~cm}-164 \\
\geq 165 \mathrm{~cm}\end{array}$ & $\begin{array}{l}4142 \\
9760 \\
3836\end{array}$ & $\begin{array}{l}23.8(3.9) \\
23.5(4.0) \\
23.0(4.0)\end{array}$ & $\begin{array}{l}5.3 \\
6.2 \\
9.1\end{array}$ & $\begin{array}{l}64.5 \\
62.6 \\
58.0\end{array}$ & $\begin{array}{l}23.6 \\
23.5 \\
25.9\end{array}$ & $\begin{array}{l}6.6 \\
7.7 \\
7.0\end{array}$ & \\
\hline
\end{tabular}

professional women, women from the Chagga tribe, and women with four or more ANC visits. Differences in mean BMI were modest, and only among mothers above 35 years of age was mean BMI above 25. The highest proportion with underweight was found among teenage mothers, mothers with missing information on education, women without partner, students, mothers from tribes other than Chagga and Pare, mothers who were missing information on ANC visits, and mothers with a height $\geq 165 \mathrm{~cm}$. Women having their second child and women with chronic hypertension or gestational hypertension or diabetes before pregnancy had a higher mean BMI and a higher proportion of overweight and obesity than women having their first child and women without these conditions (Table 2).

Preeclampsia was recorded for five hundred and eighty-two pregnancies (3.3\%). The risk of preeclampsia increased with increasing pre pregnancy BMI, maternal age, maternal educational level, and body height ( $p$-values for trend <0.05) (Table 3). Preeclampsia was more common among married women, among those working in service or professional workers, and among women from the Pare tribe.

After adjustment, overweight and obese women were 1.4 and 1.8 times more likely to have preeclampsia than women with normal BMI (95\% CI 1.2-1.8 and 1.3-2.4, 
Table 2 Maternal health related characteristics in by BMI $\left(\mathrm{kg} / \mathrm{m}^{2}\right)$ category; 17,738 singleton first or second deliveries. KCMC Medical birth registry July 2000-May 2013

\begin{tabular}{|c|c|c|c|c|c|c|c|}
\hline Maternal health characteristics & $\mathrm{N}$ & $\begin{array}{l}\text { Mean (SD) } \\
\text { BMl }\end{array}$ & $\begin{array}{l}\mathrm{BMI}<18.5 \\
\text { Underweight }\end{array}$ & $\begin{array}{l}\text { BMI 18.5-24.9 } \\
\text { Normal }\end{array}$ & $\begin{array}{l}\text { BMI 25.0-29.9 } \\
\text { Overweight }\end{array}$ & $\begin{array}{l}\text { BMI > = } 30 \\
\text { Obese }\end{array}$ & $\begin{array}{l}x^{2} \\
p \text {-value }\end{array}$ \\
\hline Overall (n) & 17,738 & & 1178 & 11,008 & 4258 & 1294 & \\
\hline$\%$ & & 23.5 & 6.6 & 62.1 & 24.0 & 7.3 & \\
\hline Pregnancy order & & & & & & & $<0.001$ \\
\hline $\begin{array}{l}\text { First } \\
\text { Second }\end{array}$ & $\begin{array}{l}10,354 \\
7384\end{array}$ & $\begin{array}{l}22.9(3.7) \\
24.3(4.1)\end{array}$ & $\begin{array}{l}8.2 \\
4.5\end{array}$ & $\begin{array}{l}66.4 \\
56.0\end{array}$ & $\begin{array}{l}20.5 \\
29.0\end{array}$ & $\begin{array}{l}5.0 \\
10.5\end{array}$ & \\
\hline Chronic hypertension & & & & & & & $<0.001$ \\
\hline $\begin{array}{l}\text { Yes } \\
\text { No }\end{array}$ & $\begin{array}{l}76 \\
17,662\end{array}$ & $\begin{array}{l}25.5(4.9) \\
23.5(3.9)\end{array}$ & $\begin{array}{l}5.3 \\
6.6\end{array}$ & $\begin{array}{l}40.8 \\
62.2\end{array}$ & $\begin{array}{l}35.5 \\
24.0\end{array}$ & $\begin{array}{l}18.4 \\
7.2\end{array}$ & \\
\hline Gestational hypertension & & & & & & & 0.02 \\
\hline $\begin{array}{l}\text { Yes } \\
\text { No }\end{array}$ & $\begin{array}{l}41 \\
17,697\end{array}$ & $\begin{array}{l}25.0(4.1) \\
23.5(4.0)\end{array}$ & $\begin{array}{l}- \\
6.7\end{array}$ & $\begin{array}{l}48.8 \\
62.1\end{array}$ & $\begin{array}{l}41.5 \\
24.0\end{array}$ & $\begin{array}{l}9.8 \\
7.3\end{array}$ & \\
\hline Diabetes* & & & & & & & 0.13 \\
\hline $\begin{array}{l}\text { Yes } \\
\text { No }\end{array}$ & $\begin{array}{l}21 \\
17,717\end{array}$ & $\begin{array}{l}24.9(4.6) \\
23.5(4.0)\end{array}$ & $\begin{array}{l}9.5 \\
6.6\end{array}$ & $\begin{array}{l}42.9 \\
62.1\end{array}$ & $\begin{array}{l}28.6 \\
24.0\end{array}$ & $\begin{array}{l}19.0 \\
7.3\end{array}$ & \\
\hline Heart disease* & & & & & & & 0.10 \\
\hline $\begin{array}{l}\text { Yes } \\
\text { No }\end{array}$ & $\begin{array}{l}53 \\
17,685\end{array}$ & $\begin{array}{l}22.5(4.5) \\
23.5(4.0)\end{array}$ & $\begin{array}{l}15.1 \\
6.6\end{array}$ & $\begin{array}{l}54.7 \\
62.1\end{array}$ & $\begin{array}{l}22.6 \\
24.0\end{array}$ & $\begin{array}{l}7.5 \\
7.3\end{array}$ & \\
\hline Gestational age & & & & & & & $<0.001$ \\
\hline $\begin{array}{l}\text { Below } 37 \text { weeks } \\
37 \text { or more weeks } \\
\text { Missing }\end{array}$ & $\begin{array}{l}2630 \\
13,675 \\
1433\end{array}$ & $\begin{array}{l}23.1(4.0) \\
23.6(3.9) \\
23.4(4.0)\end{array}$ & $\begin{array}{l}8.5 \\
6.2 \\
6.7\end{array}$ & $\begin{array}{l}64.0 \\
61.7 \\
61.5\end{array}$ & $\begin{array}{l}20.8 \\
24.7 \\
23.2\end{array}$ & $\begin{array}{l}6.7 \\
7.4 \\
7.5\end{array}$ & \\
\hline
\end{tabular}

*Before pregnancy

respectively), while underweight women were less likely to have preeclampsia (adjusted OR 0.7, 95\% CI 0.4-1.1). Mother's age, marital status and tribe remained associated with preeclampsia after adjustment, and $p$-values for trend were significant for pre pregnancy BMI, mother's age, and mother's height.

We further adjusted for selected medical conditions known to be associated with both BMI and preeclampsia, i.e. chronic hypertension, heart disease and diabetes before pregnancy. The effect of BMI then changed slightly from 1.8 in the highest BMI class to 1.7 (data not presented in table).

The association between BMI and preeclampsia was slightly stronger among mothers delivering at term than among mothers delivering preterm; adjusted OR (CI) per unit increase in BMI $1.08(1.05-1.11)$ vs 1.05 (1.01-1.08), $p$-value for interaction 0.15 .

The association between BMI and preeclampsia was slightly stronger among mothers with a height below $160 \mathrm{~cm}$ (45\% of the women) compared to mothers with a height $160 \mathrm{~cm}$ or above; adjusted OR (CI) per unit increase in BMI 1.08 (1.04-1.11) vs. 1.05 (1.03-1.09), $p$-value for interaction 0.40 .

A total of 1499 women were recorded with two pregnancies in the study population. Results from a clustered analysis accounting for correlation between births from the same mother were almost identical to the presented results (data not shown).

\section{Discussion}

We found a positive association between increasing pre pregnancy body mass index and the risk of developing preeclampsia, amounting to an adjusted odds ratio of 1.8 for obese women with BMI above 30 as compared to normal weight women with BMI between 20 and 24.9. Among the maternal characteristics included in our analysis, only maternal age above 35 years of age showed a higher odds ratio. Our findings are in line with previous studies based on populations of pregnant women in high income countries [8-12].

Using the WHO definition of overweight and obesity, the prevalence of pre pregnancy overweight and obesity in our study population of ethnic African women was $24.0 \%$ and $7.3 \%$, respectively. This compares with a study from Dar Es Salaam, where prevalence of obesity among females of reproductive age increased from 3.6\% in 1995 to $9.1 \%$ in 2004 [13]. Our results, with nearly one third of the women were overweight or obese, correspond with global numbers of obesity, showing that obesity has now become a significant health challenge also in many low income countries [19].

We had no information on severity of preeclampsia or time of onset, but used preterm birth as a proxy for severity. The association between increasing BMI and preeclampsia was strongest for preeclampsia in connection with a term delivery, although the interaction between 
Table 3 Observed and adjusted odds ratio of preeclampsia according to risk factors;17,738 singleton first or second deliveries. KCMC Medical birth registry July 2000-May 2013

\begin{tabular}{|c|c|c|c|c|c|c|}
\hline Maternal characteristics & No preeclampsia (n) & $\begin{array}{l}\text { Preeclampsia } \\
{[n(\%)]}\end{array}$ & $\begin{array}{l}\text { Crude } \\
\text { OR (95\% Cl) P-value }\end{array}$ & & $\begin{array}{l}\text { Adjusted* } \\
\text { OR }(95 \% \text { Cl) } P \text {-value }\end{array}$ & \\
\hline Mother's BMI $\left(\mathrm{kg} / \mathrm{m}^{2}\right)$ & & & & $<0.001$ & & $<0.001$ \\
\hline$<18.5$ underweight & 1153 & $25(2.1)$ & $0.7(0.5-1.1)$ & & $0.7(0.4-1.1)$ & \\
\hline $18.5-24.9$ normal & 10,694 & $314(2.9)$ & Ref & & Ref & \\
\hline 25.0-29.9 overweight & 4077 & $181(4.3)$ & $1.5(1.3-1.8)$ & & $1.4(1.2-1.8)$ & \\
\hline 30 thru highest obese & 1232 & $62(4.8)$ & $1.7(1.3-2.3)$ & & $1.8(1.3-2.4)$ & \\
\hline$P$ for trend & & & $<0.001$ & & $<0.001$ & \\
\hline Mother's age & & & & $<0.001$ & & $<0.001$ \\
\hline $13-19$ & 2090 & $61(2.8)$ & $1.1(0.8-1.5)$ & & $0.9(0.7-1.3)$ & \\
\hline $20-24$ & 6268 & $169(2.6)$ & Ref & & Ref & \\
\hline $25-29$ & 5568 & $187(3.2)$ & $1.2(1.0-1.5)$ & & $1.2(1.0-1.5)$ & \\
\hline $30-34$ & 2493 & $114(4.4)$ & $1.7(1.3-2.2)$ & & $1.6(1.2-2.1)$ & \\
\hline $35-50$ & 706 & $49(6.5)$ & $2.6(1.9-3.6)$ & & $2.6(1.8-3.7)$ & \\
\hline$P$ for trend & & & $<0.001$ & & $<0.001$ & \\
\hline Mother's education & & & & 0.08 & & 0.4 \\
\hline None & 172 & $5(2.8)$ & $0.8(0.3-1.9)$ & & $1.2(0.5-3.1)$ & \\
\hline Primary & 8839 & $277(3.0)$ & $0.8(0.7-1.0)$ & & $1.1(0.9-1.5)$ & \\
\hline Secondary (8-11) & 1111 & $31(2.7)$ & $0.7(0.5-1.1)$ & & $0.9(0.6-1.3)$ & \\
\hline Higher (12+) & 7009 & $268(3.7)$ & Ref & & Ref & \\
\hline$P$ for trend & & & 0.02 & & 0.2 & \\
\hline Pregnancy number & & & & 0.06 & & 0.001 \\
\hline First & 9992 & $362(3.5)$ & Ref & & Ref & \\
\hline Second & 7164 & $220(3.0)$ & $0.8(0.7-1.0)$ & & $0.7(0.6-0.9)$ & \\
\hline Marital status & & & & 0.003 & & 0.02 \\
\hline With partner & 14,348 & 459 (3.1) & Ref & & Ref & \\
\hline Without partner & 2746 & $120(4.2)$ & $0.7(0.6-0.9)$ & & $0.8(0.6-1.3)$ & \\
\hline Mother's occupation & & & & $<0.001$ & & 0.07 \\
\hline Housewife & 3463 & $104(2.9)$ & $1.0(0.8-1.4)$ & & $1.0(0.8-1.4)$ & \\
\hline Farmer & 2704 & $80(2.9)$ & Ref & & Ref & \\
\hline Service & 1227 & $59(4.6)$ & $1.6(1.2-2.3)$ & & $1.4(1.0-2.0)$ & \\
\hline Business & 4012 & $113(2.7)$ & $1.0(0.7-1.3)$ & & $0.8(0.6-1.1)$ & \\
\hline Professional & 3629 & $161(4.2)$ & $1.5(1.1-2.0)$ & & $1.2(0.9-1.7)$ & \\
\hline Student & 573 & $19(3.2)$ & $1.1(0.7-1.9)$ & & $1.1(0.6-1.8)$ & \\
\hline Mother's tribe & & & & $<0.001$ & & $<0.001$ \\
\hline Chagga & 9874 & $290(2.9)$ & Ref & & Ref & \\
\hline Pare & 1951 & $93(4.5)$ & $1.6(1.3-2.1)$ & & $1.9(1.4-2.4)$ & \\
\hline Others & 5531 & 199 (3.6) & $1.3(1.1-1.5)$ & & $1.5(1.2-1.8)$ & \\
\hline Mother's height & & & & 0.009 & & 0.01 \\
\hline$<155 \mathrm{~cm}$ & 4017 & $125(3.0)$ & $0.7(0.6-0.9)$ & & $0.7(0.6-1.0)$ & \\
\hline $155-164 \mathrm{~cm}$ & 9459 & 301 (3.1) & $0.8(0.6-0.9)$ & & $0.7(0.6-0.9)$ & \\
\hline$\geq 165 \mathrm{~cm}$ & 3680 & $156(4.1)$ & Ref & & Ref & \\
\hline$P$ for trend & & & 0.01 & & 0.02 & \\
\hline
\end{tabular}

*All variables are in the multivariable model 
gestational age at delivery and preeclampsia was not statistically significant. These results are consistent with a study from the Swedish birth registry where the association between increasing BMI was stronger for term preeclampsia than for preeclampsia before term [20]. A possible explanation for these findings is that early and severe preeclampsia more often originates in placenta, whereas late and mild preeclampsia is more related to metabolic disease and hence more often associated with high BMI [21].

In our data, being overweight and obese was associated with higher maternal age, being married, high education, and being from the Chagga tribe, the majority tribe in the area. This indicates that overweight and obesity in this population are associated with higher socioeconomic status rather than low socioeconomic status which is the case in resource rich countries. In our study, adjustment for socioeconomic factors had, however, little influence on the effect of BMI. Socioeconomic factors are not among major risk factors of preeclampsia [7], and, although associated with BMI, are therefore not likely important confounders.

Our study was based on women of African origin in a low income setting, but we found an association between BMI and preeclampsia that was similar both in direction and magnitude to those from resource rich countries. However, the course and outcome of a preeclamptic pregnancy may vary not only by race or ethnicity but also by available resources. It is therefore important that African women, who bear a disproportionate burden of global maternal morbidity and mortality due to preeclampsia and other pregnancy complications, are included in studies on preeclampsia.

\section{Strengths and limitations}

A strength of our study is that we used data from a registry with a systematic collection of data based on a structured interview during the 13 years study period. It is also a strength that we had information on several possible confounding factors such as socio-demography and maternal disease both before and during pregnancy.

Because the study is hospital based we cannot rule out selection bias if women who deliver at KCMC differ from women in the area who deliver at home or in other hospitals. In the Kilimanjaro region, 13\% of all deliveries take place outside a health facility, and nearly all women receive antenatal care from a skilled provider [22]. In general, selection will mostly influence prevalence estimates of exposure and outcome and to a lesser extent effect estimates. As a result of possible selection to giving birth at KCMC and also of how we selected our study population (exclusion of multifetal deliveries and women from rural areas who were referred to KCMC for medical reasons), the preeclampsia rate of 3.3\% may not reflect the rate in the population. Furthermore, poor ascertainment of the mildest forms of preeclampsia may influence the observed preeclampsia rate. Among women in Northern Tanzania who had attended ANC for their most recent birth in the last five years, 79.9\% had their blood pressure measured and $65.4 \%$ had their urine tested [22].

The mother's weight was retrieved from her antenatal record if her first antenatal visit took place before week 16 of pregnancy, otherwise self-reported weight was recorded if reasonable. Most studies report that women tend to underreport their body weight [23], but this might vary from population to population depending on how socially acceptable or desirable it is to be underweight or overweight. However, since body weight was reported before the onset of preeclampsia, reporting error in any direction most likely represents a nondifferential misclassification and therefore will tend to change the odds ratios towards 1 , i.e. give conservative effect estimates. Furthermore, unmeasured factors such as nutrition and diet might represent residual confounding and affect our results if associated with both body mass index and preeclampsia.

Our main aim was to assess the association between BMI and preeclampsia, but we also report associations between the covariates and preeclampsia. We acknowledge that multiple comparisons are a concern and that the additional tests should be regarded as exploratory.

\section{Conclusions}

'There appears to be an association between increased pre pregnancy body mass index category and increased preeclampsia risk, in this resource limited population. The increasing prevalence of obesity in pre pregnant women in low income countries hinders efforts to improve perinatal health and reduce maternal mortality. Close clinical antenatal monitoring of all pregnant women in Tanzania, especially blood pressure monitoring, is critically important, but especially so for overweight and obese women.

\section{Abbreviations}

aOR: adjusted odds ratio; BMI: body mass index; OR: odds ratio; WHO: World Health Organization

\section{Acknowledgements}

We thank all birth registry staff for their participation in data collection, and all mothers who delivered at KCMC and consented to provide information.

\section{Funding}

The birth registry at KCMC was funded by the Norwegian Council for Higher education program and Development Research (NUFU) during 2000-2010, and by KCMC from 2011. This study was sponsored by the Norwegian government through the Master's Degree Program at the Faculty of Medicine and Dentistry, University of Bergen, Bergen, Norway.

Availability of data and materials

Data was retrieved from the electronic KCMC Medical Birth Registry and transferred to project collaborators at the University of Bergen while first author DM was a master student there. For this specific master project we 
obtained a research ethical certificate from Tumaini University Makumira, Kilimanjaro Christian Medical College (certificate No. 641, Research proposal No. 633). The data will not be shared in order to protect the participants' anonymity.

\section{Authors' contributions}

DM: conception idea for the study, design of the study, data analysis, manuscript preparation and subsequent revisions. MJJ, TØ: advice in designing the study and analysis and revision of the manuscript. RTL, AKD: conception of the research idea, advice in designing the study and analysis and revision of the manuscript. All authors read and approved the final manuscript.

\section{Ethics approval and consent to participate}

Ethical approval was sought from Kilimanjaro Christian Medical University College research ethics committee prior the commencement of this study (Research Ethical Clearance Certificate No. 641, 2013). The birth registry at KCMC has ethical clearance from the Tanzania national institute for medical research (NIMR) 2003 and from the Regional National Ethics committee (Health Region III) Norway 1999. Verbal informed consent is obtained from each mother prior to the interview, and a unique maternal hospital identification number is used to protect confidentiality.

\section{Consent for publication}

Not applicable

\section{Competing interests}

The authors declare that they have no competing interests.

\section{Publisher's Note}

Springer Nature remains neutral with regard to jurisdictional claims in published maps and institutional affiliations.

\section{Author details}

'Department of Global Public Health and Primary Care, Faculty of Medicine, University of Bergen, Postboks 7804, N-5020 Bergen, Norway. ${ }^{2}$ Department of Obstetrics and Gynaecology, Kilimanjaro Christian Medical Centre, Moshi, Tanzania. ${ }^{3}$ Norwegian Institute of Public Health, Bergen, Norway. ${ }^{4}$ Institute of Public Health, Department of Epidemiology \& Biostatistics, Kilimanjaro Christian Medical University College, Moshi, Tanzania.

Received: 14 June 2016 Accepted: 12 February 2018

Published online: 21 February 2018

\section{References}

1. WHO, UNICEF, UNFPA, The World Bank. Trends in maternal mortality: 1990 to 2010. Geneva: World Health Organization; 2012.

2. Duley L. The global impact of pre-eclampsia and eclampsia. Semin Perinatol. 2009;33:130-7.

3. Ahn H, Park J, Gilman-Sachs A, Kwak-Kim J. Immunologic characteristics of preeclampsia, a comprehensive review. American journal of reproductive immunology (New York, NY : 1989). 2011;65:377-94.

4. Fong FM, Sahemey MK, Hamedi G, Eyitayo R, Yates D, Kuan V, et al. Maternal genotype and severe preeclampsia: a HuGE review. Am J Epidemiol. 2014;180:335-45.

5. Solomon CG, Seely EW. Brief review: hypertension in pregnancy : a manifestation of the insulin resistance syndrome? Hypertension. 2001:37: 232-9.

6. Fisher SJ. Why is placentation abnormal in preeclampsia? Am J Obstet Gynecol. 2015;213:S115-22.

7. Duckitt K, Harrington D. Risk factors for pre-eclampsia at antenatal booking: systematic review of controlled studies. BMJ (Clinical research ed). 2005;330: 565.

8. Cnattingius S, Bergstrom R, Lipworth L, Kramer MS. Pre pregnancy weight and the risk of adverse pregnancy outcomes. N Engl J Med. 1998:338:147-52.

9. Thadhani R, Stampfer MJ, Hunter DJ, Manson JE, Solomon CG, Curhan GC. High body mass index and hypercholesterolemia: risk of hypertensive disorders of pregnancy. Obstet Gynecol. 1999;94:543-50.

10. Sebire NJ, Jolly M, Harris JP, Wadsworth J, Joffe M, Beard RW, et al. Maternal obesity and pregnancy outcome: a study of 287,213 pregnancies in
London. International journal of obesity and related metabolic disorders : journal of the International Association for the Study of Obesity. 2001;25: 1175-82.

11. Bodnar LM, Ness RB, Markovic N, Roberts JM. The risk of preeclampsia rises with increasing pre pregnancy body mass index. Ann Epidemiol. 2005;15: 475-82.

12. Bhattacharya S, Campbell DM, Liston WA, Bhattacharya S. Effect of body mass index on pregnancy outcomes in nulliparous women delivering singleton babies. BMC Public Health. 2007;7:168.

13. Villamor E, Msamanga G, Urassa W, Petraro P, Spiegelman D, Hunter DJ, et al. Trends in obesity, underweight, and wasting among women attending prenatal clinics in urban Tanzania, 1995-2004. Am J Clin Nutr. 2006;83:138794.

14. National Bureau of Statistics. Tanzania demographic and health survey 2004-2005. Tanzania: Dar es Salaam; 2005.

15. Nakimuli A, Chazara O, Byamugisha J, Elliott AM, Kaleebu P, Mirembe F, et al. Pregnancy, parturition and preeclampsia in women of African ancestry. Am J Obstet Gynecol. 2014;210:510-20. el

16. Jeyabalan A. Epidemiology of preeclampsia: impact of obesity. Nutr Rev. 2013:71:18-25.

17. Goodwin AA, Mercer BM. Does maternal race or ethnicity affect the expression of severe preeclampsia? Am J Obstet Gynecol. 2005;193:973-8.

18. Bergsjø P, Mlay J, Lie RT, Lie-Nielsen E, Shao JF. A medical birth registry at Kilimanjaro Christian medical Centre. East Afr J Public Health. 2007:4:1-4.

19. Finucane MM, Stevens GA, Cowan MJ, Danaei G, Lin JK, Paciorek CJ, et al. National, regional, and global trends in body-mass index since 1980: systematic analysis of health examination surveys and epidemiological studies with 960 country-years and 9.1 million participants. Lancet (London, England). 2011;377:557-67.

20. Sohlberg S, Stephansson O, Cnattingius S, Wikstrom AK. Maternal body mass index, height, and risks of preeclampsia. Am J Hypertens. 2012;25: $120-5$.

21. Valensise H, Vasapollo B, Gagliardi G, Novelli GP. Early and late preeclampsia: two different maternal hemodynamic states in the latent phase of the disease. Hypertension. 2008:52:873-80.

22. Tanzania Demographic and Health Survey 2010. National Bureau of statistics, Dar es salaam, Tanzania, and ICF macro, Calverton, Maryland, USA. 2011.

23. Fattah C, Farah N, O'Toole F, Barry S, Stuart B, Turner MJ. Body mass index (BMI) in women booking for antenatal care: comparison between selfreported and digital measurements. Eur J Obstet Gynecol Reprod Biol. 2009;144:32-4.

\section{Submit your next manuscript to BioMed Central} and we will help you at every step:

- We accept pre-submission inquiries

- Our selector tool helps you to find the most relevant journal

- We provide round the clock customer support

- Convenient online submission

- Thorough peer review

- Inclusion in PubMed and all major indexing services

- Maximum visibility for your research

Submit your manuscript at www.biomedcentral.com/submit
) Biomed Central 